\title{
Paradoxical traps in therapeutics: some dilemmas in medical ethics
}

\author{
Uri Lowental The Hebrew University - Hadassahe School of Dental Medicine, ferusalem, Israel
}

\begin{abstract}
The doctor-patient relationship is examined with an emphasis on the comparison between professional and moral principles. Many therapeutic measures have opposite-directed alternative steps with an equal degree of justification, so that no logical preference is attainable and conflicts ensue.

Thus patients come for relief and are ordered to endure further pain and discomfort; or weaker individuals exaggerate their complaints hypochondriacally, and thus need a great deal of understanding, yet paradoxically they are prone to receive less support than stronger ones. Further conflicts arise between our devotion to human wellbeing and dignity, and our obligation to disrespect some of their rights for self-determination.

Furthermore, various dutifully performed doctoring activities run counter to our own social needs and interests; last, but not least, human imperfection colours some of our decisions, putting a definite blemish on their value. In conclusion, physicians must bear the constant burden of paradoxicallyopposed alternatives, and they confront pitfalls of wrongdoing at every therapeutic step. Their only guidelines are intuition and professional dedication.
\end{abstract}

The ancient Greek therapeutae (literally: attenders) were spiritualists who busied themselves with continuous intuitive meditation and contemplation. Nowadays, therapeutics has shifted and closed in upon science, thus becoming rather disconnected from intuition or philosophy. Few medical schools teach medical thinking or intuition, or embark on a course similar to Moore's ${ }^{1}$ in Melbourne, 'The Ethical Landscape', where discussions are based on passages from belles-lettres depicting doctors' and patients' dilemmas.

Yet within the last few years medical ethics has developed into a well recognised branch of research. Brody ${ }^{2}$ counted four key issues:

a) the nature of doctor-patient relationship,

b) informed consent,

c) determining the quality of life,

d) the right of participation in decision making.

One sector of the first of these issues I shall call 'the paradoxes in medical therapeutics'. Paradoxes have been used by Plato and the Sophists to argue for and against a propounded statement, a practice that later inspired the Aristotelian theory of opposi tions. Besides such logical usage, paradoxes als $\rho$ border on theology and pantheism, as in the contras $\vec{\psi}$ between the existence and the non-existence of the unique all-embracing God. This example reflects our need to believe in moral commands so as to follow them, in contrast to other rules where trainingand understanding are sufficient levers for response $N$

Having introduced the points of intuition ando belief, of a central importance in our exploration of paradoxical situations in therapeutics, we shall add $\overrightarrow{-}$ Campbell's ${ }^{3}$ distinction between 'moral' codes ô behaviour held by various groups or differens individuals, and 'ethics' which study these phenomena but provide no moral guidance. Weु shall start with a consideration of patients' interests:

\section{The patient's best interests}

By definition, becoming a patient means to endure the paradoxical conflict between pain and pleasure, $a \stackrel{a}{a}$ feature that weighs on therapeutic encounters fromo $\overrightarrow{\vec{B}}$ their outset. Many mundane activities are motivated 3 to fit the 'hedonistic theory', i.e., aimed at increased pleasure or at diminished discomfort. ${ }^{4}$ One's? motivation to receive medical aid cannot be governed $\overline{3}$ by the same principle; on the contrary, a patient is ${ }^{\Phi}$ required to repress his shame while he displays private areas of body or mind, to overcome many natural functions ("Don't breathe!") and reflexes ("Say 'ah' but don't gag!"), and is almost expected to welcome the painful needle biopsy, or the incapacitating dependency caused by psychoanalytic $\frac{D}{O}$ psychotherapy. Some people do not try to overcome their hesitation and others get tired of it, for $N$ instance Faden and Faden's ${ }^{5}$ patients who refused ${ }_{N}$ their consent for a treatment of their fractured hips, $N$ holding on to their false beliefs, creating a situation $\omega$ that provokes in the doctor conflicts over his own? paternalism.

Treatment refusal may be related to 'antimedicine' (a term suggested here to denote all ${ }^{+}$ objective disadvantages of therapy, like risks or side $\underline{T}$ effects, rather than 'a choice of unusual methods'). $\frac{\text { P }}{\mathbb{D}}$ Almost no treatment, whether a diagnostic $\frac{?}{\mathbb{Q}}$ procedure, drug, or other therapy, is without side $\stackrel{\Phi}{\varrho}$ effects; a bitter truth. ${ }^{6}$ Well-known is Illich's '? exposition to that effect, a spectacular outcry $\delta$ against 'the iatrogenic pandemic, the plethora of therapeutic side effects', which demonstrates once 
again that a non-physician can hardly comprehend why we do not adhere strictly to the principle of primum non nocere. Illich's criticism of modern medicine has evoked a reasonable resentment voiced by Halberstam ${ }^{8}$ and others.

\section{Le malade imaginaire}

Most people harbour conflicting values when it comes to health and disease: some clamp down on their suffering and never admit it, while others complain and try to receive medical support even without physical symptoms. Even if we avoid the exploration of hypochondriasis as a nosological entity, we often discern a 'hypochondriacal coefficient' in various patients, a distortion of the scientificallyaccurate report of discomfort, whatever 'scientifically' means in this context. A high coefficient of hypochondriasis evokes in physicians an emotional reaction rarely mentioned: they dislike exaggerated complainers and are led thereby into another therapeutic paradox, namely, that when a weaker patient begs for pity and encouragement (and needs $i t$, rather than medicines, more than a stronger individual!), he undermines our readiness to show our compassion. Extreme cases of this type were recently described by Groves' ${ }^{2}$ and called 'The insatiable dependency of hateful patients': the clingers evoke aversion, the over-demanders a wish to counter-attack, the help-rejecters bring about depression in the therapist, and the selfdestructive deniers create a feeling of malice. In spite of all affective responses a physician must take care of those who come for his help, whatever their deviation from the ideal patient's role-presentation.

\section{Decision-making}

Some instructive codes may direct a physician's choice between alternatives and diminish the ethical conflict involved in deciding, for example, on the list of priorities. Manuals of military medicine state the type of wounds that must be attended to first, or say that soldiers with over 75 per cent burns should be given only fluids and sedatives because they will not survive. Other questions of decision-making and preference are harder to solve, though perhaps less emotionally provoking, and they constitute real dilemmas to many of us. Must we always prefer the patient, or the institution? Prescribe the new expensive drug to many, despite the administrator's threat to stop its supply altogether? It is the drug of choice, therefore we exclaim that if he refuses it we shall resign. Is this a sign of medico-ethical behaviour?

The theologian Ramsey ${ }^{10}$ mentioned some similar dilemmas in an unvarnished manner. With the limited availability of facilities for haemodialysis, should 'the better man live'? Is the selection of a few fatal-illness patients for treatment not a 'human lottery'? Or is it the case that 'all should die when not all can survive'?

Whatever the therapeutic goal, every presumed measure has always an alternative option (Brown and Freeling $\left.{ }^{11}\right)$. One hears voices for and against antibiotic treatment of viral infections as a preventive measure, or whether children should or should not visit their friend who has chicken-pox. Paradoxically, both opposing opinions are justifiable.

\section{A patient's right for self-determination}

Here we enter the realm of a frank opposition between medical and general ethics. Every human being has, at least in theory, a right for life and a similar right for death. The recent California Natural Death Act is based on this premiss, and in several parliaments all over the world bills are being formulated to ensure the following: a person may sign a will, a statement declaring that in the event of malignant disease or other severe disablement, there will be undertaken no life-saving measures beyond analgesia and sedation, nor any attempted resuscitation. Now let us imagine an unconscious accidentvictim rushed in, profusely bleeding from an amputated arm stump, and in his one remaining fist is cramped a signed declaration stating that a missing arm is a severe disablement as mentioned. Must not the surgeon ignore any such suicidal statement, without thinking twice of alleged human honour, self-determination, or the dignity of those who signed as witnesses?

Life and death are sacred alternatives with moral sanctions crystallised into religious codes. Among Jews, for example, life must be guarded at all cost and above all other commandments. A non-religious Anschaung does allow for exceptions, as in the case of certain honourable suicide ${ }^{12}$ or serene euthanasia, which means easy dying and not easy killing. ${ }^{13}$ However, the struggling medical practitioner regards death as a seething cauldron of failure and resignation, yet he must suit himself to the inevitable and face conflicts like those evoked by a (hypothetical) dialysis-patient who refuses to continue treatment. The results are arguments like 'The function of medicine is to preserve autonomy, and the preservation of life is subservient to the primary goal'. ${ }^{14}$

The paradox grows quite formidable when medical logic is polluted by alien calculations, e.g. those enforced by malpractice-suits. Lewis ${ }^{15}$ has put it succintly: the formula of patient-physician vs. disease, is perverted to patient vs. physician vs. disease, inviting disaster. One of the resulting misconceptions is the 'no lose' philosophy described by Galbraith. ${ }^{16}$ Before a diagnosis is reached, superfluous investigations are piled up, ostensibly in order to prevent the neglect of any information, but with an excessive exposure to risks. 
Problems aroused by the physician's own interests

Malpractice-suits and their sequellae point out the antithesis of a membership in the helping profession, on the one side, and any gained profit, on the other; or between altruism and the acquisition of an income. We shall disregard the sad case of pathological deviation that has turned medicine into a profitable merchandise, and accept only the axiom: even physicians must support their families; a real challenge to conscience. One cannot improvise an easy dissection of this Gordian knot.

Another controversy of interests or roles relates to the fact that a medical diploma inspires authority, even though authority is not equivalent to power. ${ }^{17}$ Medical authority should presuppose moral responsibility, and again we stumble over a systematic ambiguity, as explained by Sumner ${ }^{18}$ : the doctor's role responsibility is a hybrid of descriptive responsibility (referring to factual treatment and results) and of normative responsibility (i.e., what the case ought to be, according to certain standards). The medical responsibility-paradox is illustrated by the everyday clash with familial obligations: should the telephoneplug stay in during intimate events at home, gatherings and parties? It is obvious that a meticulous observance of one's oath antagonises most habits of an ordinary family and social life; this, in turn, embitters and hampers one's professional efficiency. Therefore, the medical moral code leads to a sheer imperfection and to shortcomings of a doctor's performance.

The physician's central problem, imperfection, deserves a separate discussion.

\section{Human imperfection}

There are no paradoxes in cybernetic formulae, computer-diagnosis or mathematical calculation of treatment dosage. Neither is there a computer ethics. The comparison came to my mind while reading Clouser's ${ }^{19}$ humble acknowledgement of medical ethics being incapable of truly fine discrimination. All the same, a conscientious examination of various particulars of therapeutics may refine the moral codes to some extent.

For instance, a doctor's adherence to one definite school of thought; one clinician regards a certain pathological process as a definite indication for surgery, while another condemns the operation and always prefers a different intervention. Similarly, one approach to mental derangements is mainly psychopharmacological yet another psychiatrist relies only on psychotherapy. Each of the four swears on his method alone and declares the others all wrong, while actually all four achieve quite similar results. This pattern of events confirms, once more, the laxity of medicine as a science: it is human weakness that makes us hold on and swear on one theory, and let it serve as a frame of reference $\stackrel{\curvearrowright}{\unrhd}$ and provide the (deficient) conviction, with inner $\overrightarrow{5}$ doubts hidden behind demonstrated certainty.

Another case of incompatible trends is the mechanism of improved understanding via clinical $\overrightarrow{\bar{s}}$ experience. The most fruitful method to com-o prehend, integrate, and to expand knowledge, 흠 according to Popper, ${ }^{20}$ is the inspection of failures $\overline{\bar{p}}$ rather than of success. Yet this very concentration on $\mathbb{\Phi}$ failures should be avoided in therapy (or limited to the CPC, clinical pathological conference), because ${ }^{\infty}$ a therapist's non-success orientation will be sensed $\vec{O}$ by patients as an unspoken message and may $\overrightarrow{\vec{H}}$ counteract treatment. Again: the very attempt to improve one's skills hampers one's dexterity.

Outstanding among the healing circumstances is $\stackrel{\mathbb{D}}{ }$ the therapeutic encounter with critical illness, when ${ }_{-}^{G}$ individual autonomy is hedged and ethical scruplesiv highlighted. Siegler ${ }^{21}$ presented the case of a patient ${ }_{0}^{N}$ who refused further diagnostic tests despite his grave condition. He died and left his physician pondering. $\vec{z}$ Siegler listed some of his doubts, and also the determinants which seemed to influence all clinicalo decision-making: the patient's rational capacity, his $\vec{\varphi}$ age, personality structure, the nature of his illness, the doctor's system of values, and the clinical enviroment (e.g., whether it is a university hospital or a rural isolated clinic).

\section{Conclusions}

Medical professionals have been accused of vanity, as if they monopolised society and claimed respect? for an exclusive ethical status. The opposite is true:? we are servants to a never-pleased moral judge, and the constant presence of alternatives turns every choice of ours into a potential mistake. Professor? Fuchs, the Jerusalem oncologist, once said that whatever we tell a cancer patient, he may insist on the universal human right for true information, but 2 also on his equally valid right to be spared the truth.

Medicine is like a rugged blend of science, $D$ humanity, and art, and there are metaphysical inadequacies even in the scientific (supposedly exact) N ingredient. Roszak ${ }^{22}$ wrote that in the nineteenth century science had struggled for complementarity and had a tolerance for ambiguity, whereas today $\omega$ science is used just to reveal information, while knowledge has become a vague holistic synthesis ofo facts and values.

In conclusion, there seems no other choice than to $\stackrel{?}{+}$ turn back to our initial hypothesis. A physician has ${ }^{T}$ only two delicate steering-oars to guide him in his $\frac{\text { ? }}{\mathbb{D}}$ moral stumbling-along: the first is intuition, a sixth $\cong$ sense of perception and deduction necessary to $\stackrel{\square}{\square}$ adjust an appropriate therapy to every particular $\overline{0}$ patient; the second is belief, along with a professional $\rho$ dedication and a striving to develop the art of medical therapeutics despite all paradoxical pitfalls. 


\section{References}

${ }^{1}$ Moore, A R (1977). Medical humanities: an aid to ethical discussions. Fournal of medical ethics, 3, 26-32.

'Brody, H (1976). Ethical Discussions in Medicine. Boston, Little and Brown.

3Campbell, A V (1975). Moral Dilemmas in Medicine. and edition. Edinburgh and London, Churchill Livingstone.

4oung, P T (1961). Motivation and Emotion-A Survey of the Determinants of Human and Animal Activity. New York - London, Wiley.

${ }^{5}$ Faden, R, and Faden, A (1977). Patient's refusal of treatment: case histories of cancer and fractured hip. Fournal of medical ethics, 3, 133-136.

'Duffy, T P (1972). Diseases of Medical Management. In A M Harvey, R J Jones, A H Owens and R S Ross: The Principles and Practice of Medicine. Pp I67 I-1687. New York, Appleton-Century-Crofts.

'Illich, I (1976) Limits to Medicine, Medical Nemesis: The Exploration of Health. London, Marion Boyars.

${ }^{8} \mathrm{Halberstam}, \mathrm{M} \mathrm{J}$ (1978). Medicine and its critics: the reward of ignorance (editiorial). Modern Medicine, 9, $12-13$.

${ }^{\circ} \mathrm{Groves,} \mathrm{J} \mathrm{E} \mathrm{(1978).} \mathrm{Taking} \mathrm{care} \mathrm{of} \mathrm{the} \mathrm{hateful} \mathrm{patient.}$ New England fournal of Medicine, 298, 883-887.

${ }^{10}$ Ramsey, P (1975). The Patient as Person. 6th printing. New Haven and London, Yale University Press.
"1Brown, K, and Freeling, P (1976). The Doctor-Patient Relationship. 2nd edition, Edinburgh and London, Churchill Livingstone.

${ }^{12}$ Lowental, U (1976). Suicide - the other side. A factor of reality in suicidal motivation. Archives of General Psychiatry, 33, 838-842.

${ }^{13}$ Lowental, U Euthanasia - a serene voyage to death. Confina Psychiatrica (in print).

${ }^{14}$ Cassel, E J (1977). The function of medicine. Hastings center report, 7, 16-19.

${ }^{15}$ Lewis, S (1978). Observations on the American malpractice dilemma. Medical hypothesis, 4, 187-188.

${ }^{16}$ Galbraith, S (1978). The 'no lose' philosophy in medicine. Fournal of Medical Ethics, 4, 61-63.

${ }^{17}$ Lesser, A H (1975). Authority. Fournal of Medical Ethics, I, 193-195.

${ }^{18}$ Sumner, B T Jr (1977). The problem of moral responsibility in medicine. fournal of Medicine and Philosophy, 2, 330-375.

${ }^{19}$ Clouser, K D (1975). Medical ethics: some uses, abuses, and limitations. New England fournal of Medicine, 293, 384-387.

${ }^{20}$ Popper, K R (1969). Conjectures and Refutations. Revised edition. London, Routledge and Kegan Paul.

21Siegler, M (1977). Critical illness: the limits of autonomy. Hastings center report, 7, 12-15.

${ }^{22}$ Roszak, Th (1974). The master and the titan: science, knowledge, and gnosis. Daedalus, 103, 17-32. 